\title{
Clinical postcard
}

\section{Multiple look-alikes delusion}

\author{
Nicoletta Beschin ${ }^{a}$, Roberto Cubelli ${ }^{b}$, Marta Zuffi ${ }^{c}$ and Sergio Della Sala ${ }^{d, *}$ \\ ${ }^{a}$ Neuropsychological Service, Rehabilitation Unit, ASST Valle Olona, Somma Lombardo Hospital, Italy \\ ${ }^{\mathrm{b}}$ Department of Psychology and Cognitive Sciences, University of Trento, Italy \\ ${ }^{c}$ Neurology Department, Multimedica Hospital-Castellanza, Italy \\ ${ }^{\mathrm{d}}$ Human Cognitive Neuroscience, Psychology, University of Edinburgh, Edinburgh, UK
}

In this paper, we report on the observation of a polyopic variant of Capgras delusion (CD), i.e., the perceived multiplication of the misidentified person. The multiplication of delusional doubles has been reported in other illusory reduplications (Brugger, Blanke, Regard, Bradford, \& Landis, 2006), but it has been mentioned very rarely within the frame of CD. It has been observed in an adolescent experiencing autoscopic hallucinations associated with panic attacks (Chabrol \& Bonnet, 1995) and in a case of Lewy Body Disease (LBD) who, two years from onset, started to claim that there were many doubles of his wife at home, but one at a time and younger (Lucchelli \& Spinnler, 2007). Another patient with LBD who reported six imposters replacing his wife, all named Shirley, was listed in a retrospective group study (Josephs, 2007, Table 1).

"Italo" was 66 years old, married but living with a different partner for several years when, one night, he called his son to pick him up as he was troubled by several ladies unknown to him: a possible episode of extracampine hallucination (Chan \& Rossor, 2002). Emergency neurological examination and morphological scans were unrevealing.

Three years later, a series of similar delusional episodes associated with excessive daytime sleepiness alarmed his family. Sleep pattern examination revealed severe restless legs syndrome and obstructive sleep apnea. No other neurological or neuropsychological deficits were observed, although the Hamilton Depression Scale (1960) unveiled a mild form of depression-anxiety. MRI showed signs of chronic diffuse vascular pathology.

Within the next two years, his daytime confusional state further deteriorated. Brain CT showed diffuse atrophy and leukoaraiosis, more pronounced on the right hemisphere. Relatives referred that Italo frequently complained of people allegedly present who might harm him. He also presented with visual hallucinations prompted by nocturnal disorientations. A neurological diagnosis of LBD was postulated (Bertram \& Williams, 2012; Diesfeldt \& Troost, 1995).

We first saw him 5 years from onset accompanied by his partner (whom we'll call Laura) who expressed her frustration as Italo believed that she was no longer who she was but one of three lookalikes. Italo was attentive and responded swiftly to the examiner's questions. He confirmed that there were three Lauras, sharing the same alluring physical features and taking turn to address him; they ate with him and even pretended to sleep with him. He did not appear worried by the situation, only puzzled by how these three ladies could synchronize their talking so smoothly and annoyed by the fact that they were spiteful, chatted incessantly and asked him to carry out domestic chores. His neuropsychological profile is detailed in Table 1: Some performance fluctuation is common in LBD, and LDB hallucinations are frequently associated with executive dysfunctions. He showed also some behavioural and emotional disturbances, scoring 10/12 (symptoms), 21/36 (symptom severity) and 26/60 (caregiver's distress) on The Neuropsychiatry Inventory (Cummings et al., 1994). During this and all ensuing regular visits to our out-patients surgery, he never confabulated (except reporting on his delusions) spontaneously or prompted by memory or language testing; discussed other life events appropriately; showed sound and detailed autobiographical recollection, including episodes and emotions concerning his own relationships which he reported congruously. Furthermore, he proved oriented in time and

\footnotetext{
* Corresponding author. Human Cognitive Neuroscience, University of Edinburgh, 7 George Square, Edinburgh, EH8 9JZ, UK.

E-mail address: sergio@ed.ac.uk (S. Della Sala).
} 
Table 1 - Neuropsychological assessments of Italo, at onset and five and six years later. References for the tests are given in the Supplementary material.

\begin{tabular}{|c|c|c|c|}
\hline \multirow[t]{2}{*}{ Test (score range) } & \multicolumn{3}{|c|}{ Neuropsychological assessments } \\
\hline & $\begin{array}{c}\text { 1st } \\
\text { (3 y post } \\
\text { onset) }\end{array}$ & $\begin{array}{c}\text { 2nd } \\
\text { (5 y post } \\
\text { onset) }\end{array}$ & $\begin{array}{c}\text { 3rd } \\
\text { (6 y post } \\
\text { onset) }\end{array}$ \\
\hline MMSE (0-30) & 28 & 24 & 25 \\
\hline MODA (0-100) & 90.7 & 87 & 87.9 \\
\hline Raven matrices $(0-36)$ & & 13 & 21 \\
\hline Verbal judgements $(0-60)$ & & 28 & 48 \\
\hline F.A.B. $(0-18)$ & & $10^{\mathrm{a}}$ & $7^{\mathrm{a}}$ \\
\hline Weigl test $(0-15)$ & & 13 & 12 \\
\hline Cognitive estimations (42-0) & & $19^{\mathrm{a}}$ & 16 \\
\hline $\begin{array}{l}\text { Attentional visual search } \\
(0-50)\end{array}$ & & 45 & $30^{\mathrm{a}}$ \\
\hline Trail making A $(0-\infty)$ & & 76 & 77 \\
\hline Token test $(0-30)$ & & 30 & 29.5 \\
\hline Phonological fluency & 29 & 25 & 24 \\
\hline Semantic fluency & 42 & 21 & 21 \\
\hline $\operatorname{VOSP}(0-20)$ & & 20 & 19 \\
\hline Rivermead-3 (0-100) & & 70 & $63^{a}$ \\
\hline Corsi span & 4 & 4 & 4 \\
\hline Digit span & 4 & 5 & $3^{a}$ \\
\hline $\begin{array}{l}\text { Rey complex figure } \\
\text { (delay) (0-36) }\end{array}$ & & 16.5 & 8 \\
\hline $\begin{array}{l}\text { Rey word list } \\
\quad \text { (immediate) (0-75) }\end{array}$ & 37 & $19^{\mathrm{a}}$ & 30 \\
\hline Rey word list (delay) (0-15) & 6 & 3 & 6 \\
\hline $\begin{array}{l}\text { Prose memory } \\
\quad \text { (immediate) (0-8) }\end{array}$ & 7.7 & 3.3 & 4 \\
\hline Prose memory (delay) (0-8) & & 3.3 & 6 \\
\hline $\begin{array}{l}\text { Rey complex figure } \\
\text { (copy) }(0-36)\end{array}$ & & 34 & 28.5 \\
\hline Object use $(0-14)$ & & 14 & 14 \\
\hline $\begin{array}{l}\text { Intransitive gesture } \\
\text { imitation }(0-72)\end{array}$ & & 72 & 72 \\
\hline
\end{tabular}

place, and recognized and identified correctly nurses and other professionals in the hospital. Relatives never reported episodes interpretable as prosopagnosia; indeed, he scored well within the normal range (11/15) in the face recognition subtest of the Rivearmead-3 test battery (Wilson et al., 2008).

In the ensuing months, the reduplicative episodes increased considerably, and his daughter decided to take him home to his former wife. Here he denied that his wife (whom we'll call Dora) was really his wife, rather he maintained that there were three Doras, identical to one another, unpleasant and rather malicious who bored him with errands. He claimed to come to the surgery with only one of them (often the nastiest). Pressed by the examiner, he reckoned as the main idiosyncrasy the fact that the three ladies shared the same name but justified that they all dressed the same as they all dressed like "old ladies". His wife was fuming during interviews complaining that he did not help at home claiming that with the three people whom he is "paying" he should not be asked to work. Notably, meanwhile Laura went back to being a real person and only one of her.

He slowly became unable to care for himself, misjudging the outside weather, forgetting to take drugs, misplacing objects and showing behavioural regressive phenomena, for instance rivaling improperly with his grandchild.

Italo presented with progressive CD characterized by three impostors physically identical yet showing some nuances of temperament, associated with neurodegeneration, probably LBD. This phenomenon, which has been witnessed by family members and his GP and was evident during our own assessment, could be due to the combined effect of Capgraslike misidentification coupled with LBD visual hallucinations, exacerbated by sleep disturbances.

\section{Supplementary material}

Supplementary material related to this article can be found at http://dx.doi.org/10.1016/j.cortex.2016.02.012.

\section{REFERENCES}

Bertram, K., \& Williams, D. R. (2012). Visual hallucinations in the differential diagnosis of Parkinsonism. Journal of Neurology, Neurosurgery, Psychiatry, 83(4), 448-452.

Brugger, P., Blanke, O., Regard, M., Bradford, D. T., \& Landis, T. (2006). Polyopic heautoscopy: case report and review of the literature. Cortex, 42, 666-674.

Chabrol, H., \& Bonnet, D. (1995). Le syndrome de Capgras à l'adolescence: Une revue à propos d'un cas. Encéphale, 21 $477-480$

Chan, D., \& Rossor, M. N. (2002). "But who is that on the other side of you?" Extracampine hallucinations revisited. Lancet, 360(9350), 2064-2066.

Cummings, J. L., Mega, M., Gray, K., Rosenberg-Thompson, S., Carusi, D. A., \& Gornbein, J. (1994). The neuropsychiatric inventory: comprehensive assessment of psychopathology in dementia. Neurology, 44, 2308-2314.

Diesfeldt, H. F., \& Troost, D. (1995). Delusional misidentification and subsequent dementia: a clinical and neuropathological study. Dementia, 6(2), 94-98.

Josephs, K. A. (2007). Capgras syndrome and its relationship to neurodegenerative disease. Archives of Neurology, 64(12), $1763-1766$.

Lucchelli, F., \& Spinnler, H. (2007). The case of lost Wilma: a clinical report of Capgras delusion. Neurological Sciences, 28, 188-195.

Wilson, B. A., Greenfield, E., Clare, L., Baddeley, A., Cockburn, J., Watson, P., et al. (2008). The Rivermead Behavioural Memory Test - third edition (RBMT-3). London, UK: Pearson Assessment.

Received 15 February 2016 Accepted 15 February 2016 